\title{
Pioneering STEM Education for Pre-Service Teachers
}

\author{
https://doi.org/10.3991/ijep.v6i4.5965 \\ Armando Paulino Preciado Babb, Miwa Aoki Takeuchi, Gabriela Alnoso Yáñez, \\ Krista Francis, Dianne Gereluk, Sharon Friesen \\ University of Calgary, Calgary, Alberta, Canada
}

\begin{abstract}
While there have been numerous initiatives to promote and recruit students into postsecondary studies in science, technology, engineering and mathematics (STEM) around the world, traditional programs of studies for both $K$ to 12 school and teacher education still lack an integrative approach to these disciplines. Addressing this concern, the Werklund School of Education of the University of Calgary started to offer a course in STEM education for the undergraduate Bachelor of Education program. The purpose of this article is to document the first iterations of this course. We draw from narratives of four instructors, including the coordinator of the course, and administrators who were actively involved in creation and approval of the course. We describe the course and its connection to the philosophy of the program, examine the context in which this course was conceived-including both national and provincial policyand address some challenges and possibilities experienced by administrators, instructors and students during the creation and implementation of the course.
\end{abstract}

Index Terms-STEM education; teacher education; curriculum; soft skills.

\section{INTRODUCTION}

The interest in attracting students into science, technology, engineering, and mathematics (STEM) postsecondary studies permeates through academic journals and international conferences. This interest has been evident in recent and diverse interventions and outreach programs around the world. Some programs, for instance, have addressed the issue of stereotyped perceptions of the work of engineering, which could impact students' decisions to pursue STEM careers, such as the intervention described in [1] that involved 565 students from Kindergarten to Grade 12. By presenting computer-based multimedia, this intervention showed that perceptions toward the work of engineering could be changed-especially among students in the early grades. Other outreach initiatives have involved students in engineering-like activities, such as the summer camp organized by six European institutions reported in [2]. The camp focused on team-oriented activities; a multidisciplinary and multicultural approach; problem-based learning; an intensive schedule; and contact with and feedback from experts. Various partnerships between elementary and secondary schools and other institutions have been implemented also as outreach programs, as documented in [3]. These partnerships involved institutions such as provincial government, community industry, small business, and global industries. Other interventions have focused on teachers, such as the technological projects for high school described in [4] that targeted school teachers and comprised four components: conceptual knowledge; design process; systematic documentation; and independent reflective learning. Programs for teacher professional learning involving similar components have engaged teachers in co-designing science projects based on the engineering design process. One example of this is a thermodynamics project for high school reported in [5], where the authors proposed that teachers should be educated to conduct this type of project as part of their professional learning.

Although the examples of outreach initiatives and programs described above have the potential of impacting on many students, we know little about possibilities and challenges to make STEM education an integral part of teacher preparation at the university level. This topic is underexplored because STEM education courses have not been part of traditional pre-service teacher education. In the fall of 2014 the Werklund School of Education (WSE) at the University of Calgary pioneered a mandatory STEM course for all undergraduate students in the Bachelor of Education Program. National policy on STEM as well as regulations and directions on education at the provincial level were key factors in the creation of the course. Additionally, the integrative approach to STEM and the philosophy behind the pre-service education program were highly compatible. Yet, there were several challenges faced by administrators, instructors and students in the implementation of the course. In this article we extend from a presentation at the EDUCON conference ([6]) discussing possibilities and constraints in implementing this STEM education course from the collective narratives of the authors. These narratives can inform other academics and leaders who are interested in the design of STEM education programs for future teachers.

The authors of this article were four instructorsincluding the course coordinator-the associate dean of the undergraduate program, and the vice dean of WSE. We documented diverse perspectives unique to the roles that each of us played in the design and implementation of the STEM education course. The administrators provided accounts of the creation of this new course in terms of provincial policy and tensions within faculty members. They also commented on perceptions from students who participated in focus group conversation during the implementation of the course. The coordinator and the instructors described some of the challenges and possibilities of the collaborative work required to teach the course and also provided some anecdotal evidences of students' experiences from their classrooms. 
This article is organized as follows. We start by describing STEM education in the Canadian context and defining its integrative approach. Then, we provide a description of the Bachelor of Education program and the STEM Education course, with a rationale for its assignments and assessment. Subsequently, we discuss challenges and possibilities we experienced in creation and implementation of the course. This article concludes with some implications for teacher education and difficulties in researching the impact of this course.

\section{STEM EDUCATION IN THE CANADIAN CONTEXT}

Canada is not unique in promoting STEM education in recent years. However, the motivations and goals driving the discourse in this emergent field differ from one country to another. A review of eight international journals in 2012 found that the majority of research in STEM education was conducted in the United States [7]. The motivation in the United States has risen in eminence since the Sputnik-spurred education reforms during the 1960s ([8], [9]), which focused on science and mathematics. This focus is reflected in the current goals and plans that the US Department of Education published in its website. In February 2016 this website indicated that "few American students pursue expertise in STEM fields - and we have an inadequate pipeline of teachers skilled in those subjects. That's why President Obama has set a priority of increasing the number of students and teachers who are proficient in these vital fields" [10]. In the website it is clear that STEM education is situated in relation to low academic scores in mathematics and science in international high-stakes testing. The goal remains focused on mathematics and science: "move from the middle to the top of the pack in science and math."

In contrast, the Canadian discourse around STEM education is not necessarily situated in the performance in international tests. Canadian students have historically been performing well in both mathematics and sciences, scoring above the average in the Programme for International Student Assessment test by the Organisation for Economic Co-operation and Development. After the economic crisis that began in 2008, STEM-related fields started to be viewed as a cornerstone to "bounce back quickly from the current global economic downturn" by the Science Technology and Innovation Council, [11]. This council stressed the role of Canada in harnessing "science, technology and innovation to drive economic prosperity and enhance societal well-being" [12]. Considering its unique contextual affordance, it is important to understand how STEM education manifests within Canada. The case of the WSE mandatory course in pre-service teacher education provides insights into the values and philosophies of STEM education consistent with the Canadian context.

\section{INTEGRATIVE APPROACH TO STEM}

There is a widespread advocacy for STEM education; yet, there has been a discrepancy among different stakeholders about what it is and how it should be taught. For instance, the study reported in [13] found that STEM education was not well understood among teachers and school administrators. Based on 172 interviews with teachers and school administrators, the study also found that there was not a shared vision on STEM education even among those who believed it was important. The study concluded indicating that there was little evidence that STEM education existed in the involved schools. In a different study involving 220 faculty members at institutions of higher education, reported in [14], authors found that even within faculty members involved in STEM education, there was no operational definition or consistent conceptualization of STEM education. They also found that faculty members with a negative perception on STEM education considered that STEM was encroaching their funding and importance within the university.

We situate the perspective adopted in the course described in this article by drawing from the integrative approach to STEM education. While different authors have proposed different classifications for the approaches to STEM education, there is a consistency in one particular approach that combines STEM in a way that transcends individual disciplines. Bybee, for instance, described five approaches to STEM education in [8]:

Coordinate - Two subjects taught in separate courses are coordinated so content in one subject synchronizes with what is needed in another subject.

Complete - While teaching the main content of one subject, the content of another subject is introduced to complement the primary subject.

Correlate - Two subjects with similar themes, contents, or processes are taught so students understand their similarities and differences.

Connections - Use one discipline to connect other disciplines, such as using technology as the connection between science and mathematics

Combine - This approach combines two or more STEM disciplines using projects, themes, procedures, or other organizing foci.

These approaches are similar to the levels of STEM integration described by Vasquez, Sneider and Comer, who proposed, in [15], four levels of integration: disciplinary, multidisciplinary, interdisciplinary, and transdisciplinary. The transdisciplinary level corresponds to the 'combine' approach described by Bybee. In this level the integration is fully embraced and students engage in an inquiry based project combining STEM subjects in meaningful ways. The inquiry transcends individual disciplines in addressing an issue or problem. This approach not only involves factual knowledge and skills across different disciplines, but also has an emphasis on the so called $21^{\text {st }}$ Century skills ([16]) — or soft skills — such as: collaboration; critical thinking, problem solving, communication, digital literacy, creativity, and innovation. This level of full integration is also known as the integrative approach to STEM education.

The engineering design process (see for example [17]) provides an appropriate structure for the integrative approach to STEM education. This is a recognized process in engineering and has different variants. However, several authors agree that this process should focus on a problem or issue to be addressed involving at least one cycle of improvement. For instance, Truesdell, in [17], describes the following steps for the design process:

1. Define a problem

2. Brainstorm

3. Research and generate ideas

4. Identify criteria and specify constraints

5. Explore possibilities 
PAPER

PioneEring STEM EdUCATION FOR PRE-SERVICE TEACHERS

6. Select an approach

7. Develop a design proposal

8. Make a model or prototype

9. Test and evaluate the design using specifications

10. Refine the design

11. Create or make the solution

12.Communicate process and results

Although the process is presented in sequential steps, in the practice the order may not be followed and some steps may be skipped, depending on the nature and circumstances of the problem. The redesign cycle is iterative and some of the steps may be repeated a number of times.

The redesign principle of the engineering design process is also present in scientific innovation. For instance, the Museum of Paleontology of the University of California has developed a flow chart of how science works (available in [18]), in which the redesign principle is applied to the process of data collection and interpretation: preliminary findings inform further data collection, including methods and instruments. For the interested reader, Galileo Educational Network Association, an organization that provides professional development for teachers, has produced video examples of the implementation of the engineering design process in projects co-designed with teachers; the videos are publicly available in [19].

In the pre-service teacher education course implemented at WSE, there is an emphasis on the integrative approach to STEM education by meaningfully integrating different disciplines. For instance, one of the learning activities is a robotics design which, in addition to the integrative approach, focuses on the unique cognitive processes of computational thinking theorized in [20]. This integrative approach is consistent with the philosophy of the Bachelor of Education program, as explained in the following section.

\section{THE STEM EducATION COURSE}

The WSE undergraduate Bachelor of Education program has placed emphasis and care around critical awareness of the many and varied contexts in which teaching and learning happens. The school has committed to the development of excellence in teaching and learning; specialized expertise in their subject areas with an interdisciplinary approach to learning; and a recognition of the expectations as a teaching professional. Upon completing the program, students can earn interim teacher certification in the province of Alberta (western Canada). The Bachelor of Education Program is also valid for teacher certification in other provinces in Canada and around the world.

The WSE philosophy conceives teaching as a collaborative and life-long learning profession. Teachers are considered experts of learning in specializations for the elementary and secondary routes. This approach to teacher education reflects a perception of teacher knowledge as distributed across disciplines - contrasted to the perspective that all teachers should know exactly the same. In order to obtain the certificate in the Bachelor Education Program, students have to complete an undergraduate degree in a subject different from education, or its equivalence in a number of courses from a different faculty. This requirement assures that student teachers have an expertise in a particular field. Students choose a specialization for the whole program among the following list: early childhood education, English as an additional language, English language, arts, French, inclusive education, mathematics, physical education, science, second languages, and social studies. While students receive targeted courses for their specialization, they are also required to take common courses.

The STEM Education course was offered in the first semester of the Bachelor of Education Program. It was spurred by a recognition that teaching is a professional activity that involves particular characteristics, situationalcontextual factors, legal and ethical obligations, approaches to teaching and student performance, collaboration, passion, and commitment. It was also an innovation across Canada, being the only compulsory course of STEM education in a program for teacher education offered at the time this manuscript was written.

On a philosophical level, the introduction of such a course was well aligned with the overall principles that underpinned the Bachelor of Education Program at WSE. Specifically, the program was premised on "dimensions of engaged inquiry." So framed, learning to teach is conceived in terms of engagement with interpretations and populations, in a manner consistent with what Henry Jenkins and colleagues [21] described as a 'participatory culture.' Inquiry entails building knowledge, creativity, innovation, and critical thought in a manner that allows for the development of deep, conceptual and relational understanding. Dimension (see below) flags the diversity and not-always-parallel natures of the many sorts of engagement associated with learning to teach. The aim is that the sophistication and complexity of understandings are hinged to the levels or dimensions with which one is willing to engage. Briefly stated, five dimensions of engaged learning framed the conceptualization of the program:

1. Engaged in learning about learning

2. Engaged with/in specializations

3. Engaged with contemporary contexts

4. Engaged with/in teaching and learning communities

5. Engaged in ethical action

The implementation of the STEM course had clear alignment with these broader goals. The STEM course would make explicit and examine how the design process informs teachers' understanding of learning and teaching as 'designers of learning' rather than as simply 'implementers of learning.' The interdisciplinary nature of STEM aimed at addressing the broader issues in society and providing relevance for students to design meaningful learning experiences within the broader contemporary contexts found in society. These initial premises helped to conceptualize the alignment of STEM to the broader programmatic features of the Bachelor of Education program. Further, the rationale provided to the broader faculty was that students already had a mandatory first year course in the humanities, but had no similar course for the STEM disciplines. By creating a STEM course, its intent was to rebalance and reposition the value of both the humanities and sciences as a necessary, complementary and essential component to being a teacher. Mandating such a course required that all students would develop an awareness and understanding for dealing with the world as it is, and the responsibility and capacities to teach well about these broader societal issues. In this way, there was a reciprocal responsibility that this course was intended to achieve. On 
the one hand, all pre-service teachers would need to understand how STEM informs their own subject area. On the other, it also created an opening for how their subject area could inform the STEM discipline.

\section{A. Course Design}

The course intended to equip pre-service teachers with pedagogical knowledge and STEM literacy skills so that when they move into their teaching careers, they were ready to integrate STEM into their day-to-day instruction through co-curricular planning and interdisciplinary lesson design. Through this course students were expected to:

1. Develop a foundational understanding of the nature of discourse in STEM disciplines as related to teaching and learning, including STEM literacy, STEM identity, and transferring understandings across disciplines;

2. Understand and appreciate how the engineering design process can contribute to teaching and learning mathematics and science;

3. Design learning environments in STEM;

4. Identify concepts and make explicit the connections across disciplines; and,

5. Apply introductory literature related to the teaching of STEM with an emphasis on the implementation of resources, the classroom environment, diverse and innovative methods of teaching within STEM, and an introduction to the Alberta Program of Studies.

The STEM course focused on the processes of learning, rather than on the accumulation of knowledge. For instance, each learning task required students to analyze, synthesize, and critically evaluate information. Students were required to continuously make connections among STEM concepts, apply their understanding of such concepts, and reflect on their learning progression. In addition, the STEM learning tasks required them to perform written communication subtasks and to share their learning through technology and other means.

A focus on processes of learning was also considered in the design of the STEM tasks and assessment. At the beginning of the course, students received the assessment rubrics for each learning task. The rubrics provided students with expectations for each task, and were also used to provide ongoing feedback to students during class.

One central assessment strategy throughout the implementation of the STEM course was the collective review of students' work by the team of instructors. Instructors met once a week during the course sharing information and discussing students' work. This process allowed discussion around diverse perspectives on assessment for each assignment. This strategy intended to provide transparency and consistency for assessment across the different sections of the course.

\section{B. Learning Tasks}

The course comprised three learning tasks:

1. STEM Concept Study Digital Slide Show (35\% of final grade)

2. Robotics Design Process and Curriculum Connections (35\% of final grade)

3. STEM Integration Showcase (30\% of final grade)
There were differences among the early childhood sections, the elementary sections and the secondary sections of the course. For early childhood and elementary sections, the STEM Concept Study assignment focused on mathematics, whereas in the secondary sections students were asked to choose a concept from any of the STEM disciplines.

All the assignments were conducted in teams of two to three students. The Robotics Designs Process and Curriculum Connections had an individual component consisting of a narrative. The other components of the course were assessed as teamwork.

\section{1) Learning Task \#1 Concept Study}

Concept Study [22] is a collaborative learning approach for teachers. This approach conceptualizes knowledge of mathematics teachers as complex, distributed, and situated in practice. Mathematics knowledge for teachers is a contested field internationally. Although there is still a debate on its nature and how teachers should learn it, a number of replicated studies has shown that this knowledge is not about advanced mathematics-further accounts of this topic may be found in several sources in the specialized literature, for instance [22]-[24]. Rather, this knowledge entails nuanced distinctions of critical features needed to understand mathematical concepts. In particular, this mathematical knowledge for teachers involves understanding the variety of meanings, images, metaphors, and analogies associated with a mathematical concept. This strategy comprises a collective, deep study of a major concept or topic comprising its historical development; cognitive obstacles and student's common mistakes and misunderstandings; images, analogies, metaphors and exemplars used for mathematics and mathematics education; contemporary role/place outside school; and development through the whole curriculum. Although concept study has been developed for mathematics education, this approach can be used for concepts in other STEM areas.

Students in the elementary and early child sections were expected to learn about the concept of multiplication (which was deemed essential for the integration with other STEM subjects); but most importantly, they were expected to learn about concept study as a strategy for future learning in other mathematics concepts. This learning task attended a provincial government requirement of mathematics content for undergraduate programs for teacher education.

Concept Study involves iterative steps of analysis that have been refined into five levels [22]: meanings, landscapes, analogical entailments, conceptual blends, and pedagogical problem solving. The first level, meanings, is an exploration of all possible meanings of the concepts, inside and beyond mathematics. These different meanings are mapped across and beyond the curriculum in the landscapes level. Such mapping shows the development of the concepts at different school grades. The conceptual blends level refers to the process of blending mathematical concepts to create a new concept. For instance, the infinite set of solutions of a linear equation in two variables and a straight-line blend as one object in the Cartesian plane. At the pedagogical problem solving level, teachers identify issues in mathematics learning and propose solutions based on their knowledge of the concept. 
Although students were expected to conduct Concept Study, the final product did not include all their work in the concept. Rather, students had to use what they have learned to pick a rich mathematics or science problem (as described by Piggott in [25]) and create a narrated and animated digital slide show presentation. The presentation had to show the problem and a rationale for choosing it.

\section{2) Learning Task \#2 Robotics Design Process}

For this learning task students were required to use LEGO MindStorm NXT or EV3 for elementary and secondary levels. Students in the early child specialization used LEGO We-Do. The library of the WSE provided the LEGO kits for each team of students. In this assignment, students had to create their own robot challenge scenario following the robot design process described in [26]: 1) defining the problem, 2) researching and designing, 3) creating a prototype, 4) building the robot, 5) programing and testing the robot, and 6) evaluating the robot. Students were required to design, build, and program a robot that can complete a challenge. Then, they had to identify three concepts from the STEM disciplines addressed in the Robot Design Process and create a concept map that identifies STEM topics and concepts addressed in the design of robots. The concept map had to include concepts contained in circles and relationships represented by lines joining the circles with words describing the relationship. The concept map was the product of the team used for assessment - instead of the actual robot.

In addition to the concept map, each student was required to submit a 500-word maximum narrative justifying the relationships in the map and explaining the key ways in which this robotics design connected to the design process and STEM concepts, as well as the nature of participatory work and the kinds of dispositions and habits that individuals working in teams need to hone. As indicated before, this narrative was the only component of the course assessed individually.

\section{3) Learning Task \#3 STEM integration showcase}

In the last assignment students were expected to develop an idea for a STEM project that could be implemented in the $\mathrm{K}$ to 12 classrooms. The project had to be presented in a poster illustrating how it could be used for teaching. The poster was showcased in a demonstration incorporating the engineering design process-identify a problem/issue/question, design, build, test and revise-in which $\mathrm{K}$ to 12 students would engage in, included a prototypical solution to the problem/issue/question. The showcase was an open public event where pre-service teachers demonstrated their developed competencies in STEM education teaching in front of $\mathrm{K}$ to 12 teachers and students, teacher educators, researchers and their peers. The process and product of the STEM showcase were demonstrated through social media. By presenting their project in front of audience, pre-service teachers transformed their learning into public knowledge.

\section{OUR EXPERIENCES}

We, the authors, gathered as a team and provided our narratives based on our own experiences in designing and implementing this course. We brought diverse perspectives by providing accounts from instructors, the coordinator of the course, and administrators from WSE. In doing so, we included multi-faceted accounts of experiences at different stages of the course, and the course design. We engaged in multiple conversations discussing our own experiences and also shared individually written narratives. We also brought student evaluations and discussed common themes across different sections of the course. These conversations and narratives helped to identify a number of challenges and enhanced opportunities at different levels. The associate dean of the Bachelor of Education Program and the vice-dean of WSE focused on the process of creation of the course. The instructors who authored this article provided accounts on both their individual experiences and the collaborative work by the team of instructors teaching the course. We were able to comment also on students' experiences, based on our interactions with students as both instructors and administrators.

As follows, we offer our narratives on what we learned from the implementation of the STEM Education course. We present diverse perspectives toward the design and implementation of this course. We also brought in some students' voices in own narratives.

\section{A. Institutional context: Perspectives from administrators}

The creation of a STEM education course needed more than desire and commitment. Although the general idea of the course fit well within the Bachelor in Education Program approach, provincial requirements in mathematics and other academic subjects had to be met, constraining the scope in content and time for the course.

The recommendation to implement STEM, however, was a site of strong contestation among faculty. The rationale for implementing this mandatory course for all first year education students raised much debate among colleagues and students. Some of the critiques from colleagues had a clear concern about the rise of the STEM disciplines in teacher education, which they feared was part of a bandwagon attempt to create an elevated status of STEM to the demise of other disciplines. Of particular concern was the removal of one of the psychology foundations courses, which had remained steadfast in traditional teacher education programs, in order to make room for the new STEM course. The content from this course was, nevertheless, integrated into two other psychology-based courses. This tension is similar to the perceptions of faculty members described in [14].

\section{$B$. Design process: A perspective from the course coordinator}

Similar to results reported by Brown in [6], the definitions of "STEM education" across instructors varied and the visions and implementations of STEM education were not necessarily common. Having a team of educators with different expertise certainly enriched the design, but it was also a challenge, as everyone wanted to include very important aspects from their fields in a course with limited scope in time and content. This discussion has been alive amid the team of instructors teaching the STEM education course. While the course has been designed and implemented, the team remained in the continuous process of refining a common definition of STEM education.

Activities and readings for the course were negotiated during its initial design. The list of readings in the first year of the implementation, for instance, seemed at a times disconnected from the assignments of the course. Initially, the course readings and content focussed on defining how each discipline was represented in the tasks. 
PAPER

However, some of the presentations for the STEM integration showcase reflected students' weak understandings of engineering education. For instance, many students superficially considered any type of building to be engineering education (such as building structures with toothpicks and marshmallows without any rationale for the purpose and connection to science or mathematics). To further students' understandings of this topic, we followed the recommendations of the Committee on Standards for K-12 Engineering Education, [27], that the engineering design process should support the learning of mathematics and science. The choice of course textbooks and readings for the second year that the course was taught reflected this shift in focus from understanding different definitions of STEM (multi-, inter-, intra- or trans-disciplinary) to a focus on understanding the design process. The articulations of the engineering design process reflected in the prototypes and posters of STEM integration showcase indicated a much stronger understanding of engineering education in the second year.

Consistent with the engineering redesign process, this course is also under constant revision. For the third iteration of the course, we intend that students further their understandings of how mathematical concepts are modelled in their projects presented at the STEM integration showcase. This involves changes to the course readings, the learning task descriptions, and the assessment criteria to reflect the intended deepening of learning. A new text is being written to support our notions of how disciplines inform STEM (including mathematical modelling) and to provide a Canadian context for the students.

Another challenge faced by the team of instructors teaching the course was related to the open nature of the tasks. For instance, in the Robotics Design Process students chose their own challenges and many questions regarding programming the LEGO MindStorm robots were very particular to their interests, making it difficult for instructor to provide support to these students. The weekly meetings with other instructors certainly helped finding suggestions for students.

\section{Challenging students' pre-conceptions: Perspectives from course instructors}

The STEM education course challenged some of the ways in which students conceptualized learning and teaching. Early focus interview groups following the first iteration of the course suggested that students seemed to see the relevance and applicability both to the STEM discipline and to inform their teaching more broadly. Some students stated that they were initially skeptical of relevance and applicability of the STEM education course to their teaching careers. Those students who were not from sciences backgrounds had tremendous anxiety and fear about how they would successfully engage in the course content. Ironically, some students from sciences backgrounds struggled. They had preconceived notions that the course would be easy and condescending to them, who had taken many courses in the area of science, technology, engineering and mathematics. However, as illustrated earlier, this course has not been focused on particular content of individual STEM disciplines, but rather on STEM literacy, with a focus on the engineering design process.

During the course of the Robotics module, some preservice teachers changed their conceptualization of learn- ing. Trial-and-error and multiple iterations of design were initially met with frustration and failure, especially given the time constraints those pre-service teachers face during the intense teacher education program. Over time, those who were intrigued by the design of robots started to embrace the "failure" of their attempts and feel a sense of accomplishment and joy of discovering a new path through multiple experiments and adjustments.

Pre-service teachers who participated in the section of the course that was focused on Early Childhood faced additional challenges when tailoring or adapting activities to create developmentally appropriate robotics tasks for early learners. Challenges included the selection of mathematics and science content that matched the cognitive capacities of early learners, as well as the limited literature available on Early Childhood STEM education to supports or guide teacher's practice: Most text-books and course readings focused on elementary and secondary education settings.

The Robotics challenge scenarios that students formulated were diverse and reflected their personal interests. For example, one group conducted research on how to clean oil-spills in our waters and learned, from their own research, how to use hay to soak oil-spills and clean up the water. This group designed a Robotics challenge scenario of carrying the hay to the oil-spill area and collecting the oil-soaked hays. For this group, their awareness of environmental issues motivated them to take on this challenge. Similarly, another group also designed a Robotics challenge scenario based on their interests in environmental issues. The challenge scenario focused on categorizing composts to facilitate recycling, by using color sensors. Another group simulated a nursing robot that can pick up a patient from a bed and carry the person to another place. This group tried multiple attempts to adjust the speed and angle of the robot's arm so that the patient would be comfortably carried.

Students were encouraged to bring their own expertise in the project. This helped them to engage in an integrative approach to STEM education in this learning task. For instance, a team decided to create a catapult robot that could be used to extinguish a fire. The design of the robot was informed by a historical review of the different types of catapults, including shape and materials. This was an important link that they related to physics during prototype design. Another group that designed a recycling robot combined their knowledge of mathematics for programming with their interests in science and environmental issues in a meaningful way.

As described earlier, at the beginning of the course many pre-service teachers expressed fear and anxiety towards STEM disciplines because the majority of them came from a humanities and/or social sciences background. Only a few received postsecondary science and mathematics education. Considering the huge amount of fear and anxiety they expressed at the beginning of this course, their engagement and creativity exhibited through the Robotics module were outstanding. Although we faced time constraints, which could hinder pre-service teachers to fully explore the design process through multiple iterations of design processes, engaging in Robotics projects challenged the way in which pre-service teachers conceptualize learning and teaching. 
PAPER

The Robotics challenge task offered pre-service teachers an opportunity to evaluate the pre-conceived notion of teaching as well, where the teacher is the center of expertise and acquisition of knowledge as a unidirectional process. The central guideline used for the Robotics module was the Design Process. Working successfully with others was a challenge for some groups of students and they were prompted to reflect on what successful group work would look like and how each member of a group could contribute to generating a meaningful learning experience. Supporting a meaningful collaboration and teamwork among students has been a challenge, as this course heavily uses group work.

It is worth reminding that the course did not assess the actual robot. Rather, the assessment focused on the design process and the connections between the STEM concepts involved in the project. It is plausible that students' levels of stress were reduced and students were more willing to take risks, due to this focus.

When three of the instructors reviewed students' evaluations together, we came up with one common thread across students' comments on the course: STEM integration. Students became aware of how different disciplines in STEM could be meaningfully connected and showed interests in exploring this integration further.

\section{CONCLUSION}

In this article we described possibilities and constraints we experienced in implementing a STEM education course in a pre-service teacher education program, by examining the case of WSE, wherein a first STEM education course started to be implemented in a teacher education program. We provided multiple perspectives from administrators, the course coordinator, and instructors. The course represented innovation in teacher education. While an integrative approach to education is not new, a compulsory course on STEM-with an integrative approach-for pre-service teachers was not offered previously in Canada, as far as we know.

In the STEM education course there was a focus on connecting and integrating ideas from a variety of disciplines, professions or technologies turning that into usable knowledge to undertake a provocative question, address a contentious issue, solve a complex problem or accomplish a complex task. This approach contrasts to a common denomination of STEM careers, which include undergraduate program in science and mathematics, with little or no connection to each other, or to technology and engineering.

The implementation of a STEM Education course was well connected with the overarching philosophy of the teacher education program. The Undergraduate Education program at the WSE conceives teachers as experts of learning in specializations for the elementary and secondary routes. This approach conceptualizes teaching as a collaborative work with distributed expertise-as opposed to a conception in which every teacher should know the same. From this perspective, teachers with specialization in Arts, Language, and Social Sciences have great potential to contribute to STEM related projects. In fact, they can bring perspectives that would enrich students' learning experiences.

Our narratives shared in this article show that the creation and incorporation of the STEM Education course has been a complex and complicated endeavour. Provincial government requirements and local circumstances in the WSE shaped, but also constrained the content and scope of the course. The diverse perspectives on STEM education held by the team of teacher educators have informed and will keep informing the design and implementation of the course. Instructors' anecdotal accounts demonstrate how some of the students' pre-conceived notions of learning and teaching were challenged through the course, by emphasizing STEM literacy.

The integration of STEM at school level can provide an opportunity for students to engage in authentic tasks with a focus on developing both hard and soft skills. Disciplinary knowledge is required to engage in the tasks. At the same time, $21^{\text {st }}$ Century learning skills such as organization, communication, group-work, and project monitoring can be fostered in STEM projects. Teachers need to develop particular skills and knowledge to design and enact such projects in the classroom. Early childhood STEM education is critical for building a foundation of concepts, knowledge, and skills related to STEM subjects. However, our experience with pre-service teachers working with early learners showed that for many teachers, the integration of robotics and computational-programming activities was challenging given the demands of early learners.

The STEM course has an additional value to teacher student education. The engineering redesign process can be a fundamental part not only for STEM education, but also as a strategy for design teaching learning environments for other fields - such as Language Arts and Social Sciences.

The description of the STEM Education course that we offered in this article is based on our own narratives. This article is our first step in documenting this innovative course and we believe that it is a valuable contribution for other scholars, teacher educators and educational institutions who are interested in implementing an integrative approach to STEM education. However, further research on this innovation is required to provide stronger evidence on the impact of this innovation, as well as the strategies that would support the implementation of similar programs. One of the significant research venues will be on the impact on pre-service teachers' teaching practices. While we can document what pre-service teachers learn in the course, it is imperative to study how they implement this learning in both other courses in the Bachelor of Education program and in their own classrooms. Another venue for future research is the development of STEM education course design as we have implemented this course twice and will continue redesigning and reimplementing it in the subsequent years.

\section{REFERENCES}

[1] A. M. Johnson, G. Ozogul, M. D. DiDonato, and M. Reisslein, "Engineering perceptions of female and male K-12 students: Effects of a multimedia overview on elementary, middle-, and high-school students," Eur. J. Eng. Educ., no. September, pp. 113, Jul. 2013.

[2] P. G. Larsen, J. M. Fernandes, J. Habel, H. Lehrskov, R. J. C. Vos, O. Wallington, and J. Zidek, "A multidisciplinary engineering summer school in an industrial setting," Eur. J. Eng. Educ., vol. 34, no. 6, pp. 511-526, Dec. 2009. https://doi.org/10.1080/ 03043790903150687

[3] J. Watters and C. Diezmann, "Community partnerships for fostering student interest and engagement in STEM," J. STEM Educ., vol. 14, no. 2, pp. 47-56, 2013. 
[4] M. Barak, "From 'doing' to 'doing with learning': Reflection on an effort to promote self-regulated learning in technological projects in high school," Eur. J. Eng. Educ., vol. 37, no. 1, pp. 105-116, Mar. 2012. https://doi.org/10.1080/03043797.2012. 658759

[5] A. P. Preciado Babb, C. Saar, S. Friesen, and J. Brandon, "Engaging high school students in an engineering thermodynamics project," iJEP, vol. 5, no. 1, pp. 12 - 19, 2015.

[6] A. P. Preciado Babb, T. Miwa, G. Dianne, G. Alonso Yáñez, F. Krista, and S. Friesen, "Pioneering STEM in undergraduate education: A course for pre-Service teachers," in 2016 IEEE Global Engineering Education Conference (EDUCON 2016): Proceedings of a meeting held 10 to 13 April 2016, Abu Dhabi, 2016, pp. $324-331$.

[7] J. Brown, "The current status of STEM education research," $J$. STEM Educ., vol. 13, pp. 7-12, 2012.

[8] R. W. Bybee, The case for STEM weducation: Challenges and opportunities. NSTA Press, 2013.

[9] R. W. Bybee, "What is STEM education?," Science, vol. 329, no. 5995, p. 996, Aug. 2010. https://doi.org/10.1126/science.1194998

[10] U.S. Department of Education, "Science, Technology, Engineering and Math: Education for Global Leadership," 2015. [Online]. Available: http://www.ed.gov/stem. [Accessed: 22-Nov2015].

[11] S. P. S. Government of Canada, Industry Canada, National Capital Region, Office of the Deputy Minister, Senior Associate Deputy Minister, "State of the Nation 2008 - STIC." Industry Canada, 2009.

[12] S. P. S. Government of Canada, Industry Canada, National Capital Region, Office of the Deputy Minister, Senior Associate Deputy Minister, "State of the Nation 2012 - STIC." Industry Canada, 2013

[13] R. Brown, J. Brown, K. Reardon, and C. Merrill, "Understanding STEM: Current perceptions," Technol. Eng. Teach., vol. 70, no. 6, pp. 5-9, 2011

[14] J. M. Breiner, C. C. Johnson, S. S. Harkness, and C. M. Koehler, "What is STEM? A discussion about conceptions of STEM in education and partnerships," Sch. Sci. Math., vol. 112, no. 1, pp. 3-11, 2012. https://doi.org/10.1111/j.1949-8594.2011.00109.x

[15] J. A. Vasquez, C. Sneider, and M. Comer, STEM lesson essentials, Grades 3-8: Integrating science, technology, engineering, and mathematics. Heinemann, 2013.

[16] M. Binkley, O. Erstad, J. Herman, S. Raizen, M. Ripley, M. Miller-Ricci, and M. Rumble, "Defining twenty-first century skills," in Assessment and teaching for 21st century skills, P. Griffin, B. McGaw, and E. Care, Eds. New York, NY: Springer, 2012, pp. 17-66.
[17] P. Truesdell, Engineering essentials for STEM instruction: How do I infuse real-world problem solving into science, technology, and math? ASCD, 2014.

[18] University of California Museum of Paleontology, "How science works: The flowchart," 2013. [Online]. Available: http://undsci.berkeley.edu/article/scienceflowchart.

[19] Galileo Educational Network, "Classroom examples: High school: Science," 2015. [Online]. Available: http://galileo.org/classroomexamples/classroom-examples-high-school-science/. [Accessed: 20-Nov-2015].

[20] P. Sengupta, J. S. Kinnebrew, S. Basu, G. Biswas, and D. Clark, "Integrating computational thinking with K-12 science education using agent-based computation: A theoretical framework," Educ. Inf. Technol., vol. 18, no. 2, pp. 351-380, 2013. https://doi.org/10.1007/s10639-012-9240-x

[21] H. Jenkins, Confronting the challenges of participatory culture. The MIT Press, 2009.

[22] B. Davis and M. Renert, The math teachers know: Profound understanding of emergent mathematics. New York: Routledge, 2014.

[23] B. Davis and E. Simmt, "Mathematics-for-teaching: An ongoing investigation of the mathematics that teachers (need to) know," Educ. Stud. Math., vol. 61, no. 3, pp. 293-319, 2006. https://doi.org/10.1007/s10649-006-2372-4

[24] H. C. Hill, D. L. Ball, and S. G. Schilling, "Unpacking Pedagogical Content Knowledge : Conceptualizing and Measuring Teachers 'Topic-Specific Knowledge of Students," vol. 39, no. 4 pp. 372-400, 2013.

[25] J. Piggott, "Rich tasks and contexts," Nrich enriching mathematics, 2008 [Online]. Available: http://nrich.maths.org/5662. [Accessed: 20-Nov-2015].

[26] Galileo Educational Network, "Robotics Design Process," 2014 [Online]. Available: http://www.galileo.org/robotics/design.html. [Accessed: 20-Nov-2015]

[27] Committee on Standards for K-12 Engineering Education; National Research Council, Standards for K-12 Engineering Education? Washington, D.C., 2010.

\section{AUTHORS}

Armando Paulino Preciado Babb, Miwa Aoki Takeuchi, Gabriela Alnoso Yáñez, Krista Francis, Dianne Gereluk, and Sharon Friesen are with the Werklund School of Education, University of Calgary, Calgary, Alberta, Canada (apprecia@ucalgary.ca).

This article is an extended and modified version of a paper presented at the EDUCON2015 conference held in Abu Dhabi, UAE, 10-13 April 2016. Submitted 25 June 2016. Published as resubmitted by the authors 1 November 2016. 